\title{
Bacterial skin infections in cirrhotics
}

\author{
Mayank Jain - Chandrashekhar Waghmare • \\ Sagar Adkar • Ajay Jain • Shohini Sircar
}

Published online: 23 March 2013

(C) Indian Society of Gastroenterology 2013

Sir,

Cellulitis is defined as an acute bacterial infection involving the skin and subcutaneous tissue, including the superficial fascia. The most common causative organisms are Streptococcus pyogenes and Staphylococcus aureus. Critically ill patients, including cirrhotics, are predisposed to cellulitis due to impaired immune status and altered skin flora [1]. In a large study from Taiwan, $6.7 \%$ patients with cirrhosis developed cellulitis compared to $4 \%$ amongst controls [2]. We wish to report our experience of bacterial skin infections in patients with cirrhosis, who were admitted in our hospital from January to September 2012. During this 9-month period, 103 patients with cirrhosis were admitted. Nine (all male) patients of mean age 50.1 (range, 22-64) had bacterial skin infection. The etiology of cirrhosis included alcohol (four), hepatitis C (three), nonalcoholic steatohepatitis (one), and hepatitis B (one). The mean (range, Model for End-Stage Liver Disease [MELD] scores) and serum albumin were 17.88 (9-29) and $2.37 \mathrm{mg} \%$ (1.3-3.1 $\mathrm{mg} \%$ ), respectively. Six patients belonged to Child-Turcotte-Pugh class B and three to class $\mathrm{C}$. Three patients had history of walking barefoot at home. Other associated infections like spontaneous bacterial peritonitis and pneumonia were seen in three and two patients, respectively. A history of smoking (four), chronic venous insufficiency (two), and ongoing interferon therapy (one) were present in some patients. The clinical picture of infection was cellulitis in eight patients, and hemorrhagic bullae were noted in one patient. Blood culture showed growth of Escherichia coli (three), S. aureus (three), Methicillin-resistant Staphylococcus Aureus (one), Klebsiella (two), Streptococcus (one), and Citrobacter (one). Culture from two patients yielded polymicrobial growth and one no growth. All patients were given magnesium sulfate dressing and broad-spectrum antibiotics, and two patients required incision and drainage. Two patients

M. Jain $(\bowtie) \cdot$ C. Waghmare $\cdot$ S. Adkar $\cdot$ A. Jain $\cdot$ S. Sircar

Department of Gastroenterology, Choithram Hospital

and Research Centre, Indore 452 017, India

e-mail: mayank4670@rediffmail.com expired (mean MELD, 22; SBP present; mean serum albumin, $2.2 \mathrm{~g} / \mathrm{dL}$ ) while seven patients (mean MELD, 16.9; mean serum albumin, $2.4 \mathrm{~g} / \mathrm{dL}$ ) improved. Thus, the mortality rate was $22.2 \%$. Skin and soft tissue infections occur in $2 \%$ to $11 \%$ of patients with chronic liver disease [3]. E. coli was a frequent cause of infection in cirrhotics unlike other patients. This is due to increased bacterial translocation across the gut and defective bactericidal function of the immunoglobulins including IgM antibodies against $E$. coli [4]. Leg edema and chronic venous insufficiency predispose to cellulitis, and this is frequently seen in cirrhotics. In a study from Chennai, in 200 newly diagnosed patients with cirrhosis, outdoor barefoot walking and serum albumin $<2.5 \mathrm{mg} / \mathrm{dL}$ were strong risk factors for skin infection in cirrhotics; $E$. coli was the most frequently identified organism, and mortality was $19 \%[5]$.

To conclude, the prevalence of bacterial skin infection in hospitalized cirrhotics was $8.7 \%$, Staphylococcus (four) and E. coli (three) were the major infective organisms, and nearly a fifth of the patients expired. Bacterial skin infections are a common and serious problem in end-stage chronic liver disease and may need strategies for prevention.

\section{References}

1. McConnell KW, Kirby JP, Mazuski JE. Cellulitis/fascitis/myositis. In: Koleff M, Isakow W (eds). The Washington Manual of Critical Care. 2nd ed. Philadelphia: Lippincott Williams and Wilkins; 2011. p. 311-6.

2. Lin M, Tsai C, Hung T, Tsai C. The risk of cellulitis in cirrhotic patients: a nationwide population based study in Taiwan. Gut Liver. 2012;6:482-5.

3. Corredoria JM, Ariza J, Pallares R, et al. Gram negative bacillary cellulitis in patients with hepatic cirrhosis. Eur J Clin Microbiol Infect Dis. 1994;13:19-24.

4. Bjornboe M, Prytz H, Orskov F. Antibodies to intestinal microbes in serum of patients with cirrhosis of liver. Lancet. 1972;1:58-60.

5. Mohan P, Ramu B, Bhaskar E, Venkataraman J. Prevalence and risk factors for bacterial skin infection and mortality in cirrhosis. Ann Hepatol. 2011;10:15-20. 